\title{
Surveillance for early stages of colon cancer: potentials for optimizing follow-up protocols

\author{
Elisa Gilardoni ${ }^{1}$, Davide Paolo Bernasconi ${ }^{2}$, Silvia Poli ${ }^{1}$, Mattia Garancini ${ }^{1}$, Margherita Luperto ${ }^{1}$, Nicola Zucchini ${ }^{3}$, \\ Giorgio Bovo ${ }^{3}$, Mauro Totis ${ }^{1}$, Alvaro Bugatti ${ }^{1}$ and Luca Gianotti ${ }^{1,4^{*}}$
}

\begin{abstract}
Background: Although several meta-analyses showed the positive effects of follow-up on the prognosis of colon cancer (CC), international guidelines are not in accordance on appropriate tests and their time frequency to optimize surveillance. Furthermore, stratified strategies based upon risk grading have not been implemented. This approach may be useful to rationalize resources.

Methods: From 2006, all patients operated for an early stage CC (I, IIA, IIB) according to the 7th edition of the AJCC-2010 classification entered in a prospective surveillance program in accordance to our local guidelines. Patients who underwent surgical resection after 2009 have been excluded to guarantee at least a 5-year follow-up. Classic histopathologic prognostic factors such as grade, T and N status, lymphatic and vascular invasion were assessed. Moreover, tumor budding and tumor-to-stroma proportion were evaluated.

Results: We had complete records of 196 patients. Distribution was as follows: 65 (33.2 \%) in stage I, 122 (62.2 \%) in stage IIA, and 9 (4.6\%) in stage IIB. Eleven patients (5.6\%) had a disease recurrence (local or distant). The median recurrence time was 20 months (range 6-48). Nine patients (82\%) had recurrence with 24 months, and $91 \%$ were asymptomatic and detected by ultrasound or CT scan. According to the log-rank test, the risk factors with significant effect on the disease-free survival (DFS) were the number of lymph nodes $<12(p=0.027)$ and the vascular invasion ( $p=0.021$ ), while for the overall (OS), only the vascular invasion was significant $(p=0.043)$. By the univariate and multivariate analyses, DSF was significantly lower in patients with less than 12 nodes removed, with vascular invasion, and with left of double cancer. OS was negatively affected only by vascular invasion despite the hazard ratios were similar to DSF. Stage IIB was associated with a threefold-increased risk of reduced OS and DSF.

Conclusions: Stages I and IIA appear to behave similarly and should be considered as true early stages. The detection of fibrosis and budding do not seem to add valuable information for prognosis. In early CC stages, the surveillance program should be maximized within the first two years.
\end{abstract}

Keywords: Colon cancer, Surveillance, Follow-up, Early stage, Surgery

\section{Background}

The prognosis of colon cancer $(\mathrm{CC})$ has improved over the years due to the earlier detection of the disease and improved surgical techniques and more effective chemotherapy.

In the management of early stages of $\mathrm{CC}$, surgery alone remains the best treatment option. Despite the

\footnotetext{
*Correspondence: luca.gianotti@unimib.it

'Department of Surgery and Translational Medicine, Milano-Bicocca

University, San Gerardo Hospital, Monza, Italy

${ }^{4}$ Department of Surgery, San Gerardo Hospital (4 piano A), Via Pergolesi 33, 20052 Monza, Italy

Full list of author information is available at the end of the article
}

excellent prognosis of early stages, the possibility of local recurrence and appearance of metachronous metastases exists, and it is directly correlated with some well known risk factors such as occlusion or perforation at presentation, TNM classification, vascular and lymphatic invasion, number of nodes retrieved, tumor grading, KRAS, BRAF mutation, and microsatellite instability [1-5]. Recently, other histopathologic features of $\mathrm{CC}$ such as tumor budding [6-8] and the presence of fibrosis $[9,10]$ have been recognized as important negative predictive factors. However, the prognostic performance of these 
new elements has not been fully validated in all cancer stages.

Surveillance remains a cornerstone approach to detect recurrence at an early stage $[11,12]$ and consequently to plan further therapeutic strategies. Although several meta-analyses have been performed on the positive effects of the follow-up on CC prognosis [13, 14], international guidelines are not in accordance on appropriate tests and their time frequency to optimize surveillance [15-18]. Furthermore, stratified strategies based upon risk scaling have not been implemented. This approach may be useful to rationalize resources.

The aims of this study were to identify predictors of recurrent disease and long-term survival among subjects operated for early stages (I, IIA, IIB) of CC defined according to the latest edition of the American Joint Committee on Cancer (AJCC) [19] and to determine potential recommendations for a optimize follow-up protocol.

\section{Methods}

Since 2006, we prospectively recorded in an electronic database all the clinical and pathological data, and the office visits of all patients operated for $\mathrm{CC}$ at the Department of Surgery of the Milano-Bicocca University-San Gerardo Hospital.

All patients entered in a surveillance program in accordance to our local guidelines (Table 1). All patients underwent contrast-enhanced abdominal ultrasound. In cases of unclear results of CEUS imaging, a contrastenhanced CT scan was done.

From this database, we retrospectively selected patients with a potentially curative resection and an early stage disease (I, IIA, IIB) according to the 7th edition of the AJCC-2010 classification [19] and operated between 2006 and 2009. We defined a radical resection (R0) when the resection margins were $\geq 5 \mathrm{~cm}$, and circumferential margins were not involved. Patients who underwent surgical resection after 2009 have been excluded to guarantee at least a 5-year follow-up.
All cases have been reviewed by two GI pathologists (GB and NZ) at double-headed microscope to confirm the following histopathologic prognostic factors: grade, $\mathrm{T}$ and $\mathrm{N}$ status, lymphatic and vascular invasion. Tumor budding (isolated single cancer cells or cluster composed of fewer than five neoplastic cells) has been evaluated in each tumor as described by Ueno et al. [6, 7]; fields with most prominent budding at the tumor invasive margin were selected and a count of the foci of budding was made with a $\times 20$ objective. Tumor budding was considered positive when bud count was higher than 9 . Tumor-to-stroma proportion has been evaluated applying Huijbers et al. criteria [9]. The stroma percentage has been estimated at the most invasive area of each tumor at $\times 10$. Each case has been given a tenfold scoring percentage and further grouped into the high-stroma $(>50 \%)$ or low-stroma $(\leq 50 \%)$ category for statistical analysis.

\section{Statistics}

Descriptive statistics of the risk factors considered were computed separately for the patients with and without recurrent disease. Two end-points were considered: disease-free survival (DFS), defined as the time elapsed from the intervention to relapse or death in absence of relapse or end of the follow-up, and overall survival (OS), defined as the time elapsed from the intervention to death by any cause or end of the follow-up. The Kaplan-Meier survival curves were estimated for the two end-points and for each risk factor, and were compared using the log-rank test. Finally, the effect of the risk factors on the two end-points was evaluated with both univariate and multivariate regression analyses, using the Cox model. All $p$ values $<0.05$ were considered significant. The $\mathrm{R}$ software version 3.0.2 was used for statistical analyses.

\section{Results}

In the study period, a total number of 567 patients were operated on for CC. Three hundred and thirty-eight

Table 1 Routine surveillance protocol according the local guidelines

\begin{tabular}{|c|c|c|c|c|c|}
\hline $\begin{array}{l}\text { Months after } \\
\text { operation }\end{array}$ & $\begin{array}{l}\text { Medical history and } \\
\text { physical examination }\end{array}$ & $\begin{array}{l}\text { Complete blood count } \\
\text { (CEA, CA 19-9 included) }\end{array}$ & $\begin{array}{l}\text { Contrast-enhanced } \\
\text { abdominal ultrasound }\end{array}$ & $\begin{array}{l}\text { Abdominal and chest } \\
\text { computed tomoghapy }\end{array}$ & Colonoscopy \\
\hline 6 & $x$ & $x$ & $x$ & & \\
\hline 12 & $x$ & $x$ & & $x$ & $x$ \\
\hline 18 & $x$ & $x$ & $x$ & & \\
\hline 24 & $x$ & $x$ & & $x$ & \\
\hline 30 & $x$ & $x$ & $x$ & & \\
\hline 36 & $x$ & $x$ & & $x$ & $x$ \\
\hline 48 & $x$ & $x$ & $x$ & & \\
\hline 60 & $x$ & $x$ & & & $x$ \\
\hline
\end{tabular}


patients were exclude, 37 in stage 0 ; 48 in stage IIC; 144, in stage III; 105 in stage IV. Two hundred and thirtythree subjects with stage I, IIA, or IIB were selected. Thirty-four patients (14.6\%) were excluded for incomplete or lost at follow-up and three patients for incomplete data for pathology examination. A final population of 196 patients with complete records was distributed as follows: 65 (33.2 \%) in stage I, $122(62.2 \%)$ in stage IIA, and $9(4.6 \%)$ in stage IIB.

Eleven patients $(5.6 \%)$ had a disease recurrence (local or distant). The characteristics of the overall population and of the patients with and without recurrence are described in detail in Table 2. No significant differences were observed when patients with and without recurrence were compared with the exception of cancer site. Subjects with tumor of the left colon and multiple cancer location were at significant higher risk of recurrence. We observed a trend toward a significant increase of risk for patients with less than 12 nodes retrieved, presence of vascular and lymphatic invasion and high presence of fibrosis.

Table 3 shows the characteristics of the patients with recurrence, the site and timing of recurrence and the diagnostic tools used to prove it. Adjuvant chemotherapy was prescribed in 2 cases: one for cancer perforation and one for the small number of lymph nodes removed $(n=5)$ and massive lymphatic/vascular invasion. The mean recurrence time was 20 months from surgery (range of 6-48 months). In nine out of eleven patients (81.8\%), recurrence was within 24 months, and in all cases but one $(90.9 \%)$, recurrence was asymptomatic and detected by ultrasound or CT scan. Two patients had local recurrence, three pulmonary, one local and pulmonary, and five hepatic metastases. The KaplanMeier estimates $(95 \% \mathrm{CI})$ of the DFS and OS on the whole sample at 5 years after diagnosis were 0.878 $(0.829-0.929)$ and $0.905 \quad(0.860-0.953)$, respectively (Fig. 1). According to the log-rank test, the risk factors with a statistically significant effect on the DFS were the number of lymph nodes $<12(p=0.027)$ and the vascular invasion $(p=0.021)$, while for the OS only the vascular invasion was significant $(p=0.043)$. These results are shown graphically by the Kaplan-Meier curves of Fig. 2 (DFS) and Fig. 3 (OS).

By the univariate analysis, DSF was significantly lower in patients with less than 12 nodes removed, with vascular invasion, and with left or double cancer. From a statistical point of view, OS was negatively affected only by vascular invasion despite the hazard ratios being similar to DSF. Stage IIB was associated with a threefoldincreased risk of reduced OS and DSF, but the data might have generated bias for the small number of patients. By the multivariate analysis, the risk factors for decreased OS and DSF confirmed the results of the univariate analysis but only left and double cancer reached statistical significance (Table 4).

\section{Discussion}

The main potential benefit of implementing follow-up programs is the early detection and subsequent treatment of disease relapse particularly when recurrence is asymptomatic [20]. The major challenge for any health care provider is to find a reasonable balance between optimal time intervals of surveillance visits and radiological imaging and health care resources used to provide these examinations. If on one side, patients derive a sense of well-being and reassurance with regular follow-up, on the other a strict surveillance may create anxiety prior to their visit and potential of false positive tests may result in further concern.

Recently several scientific societies and groups of experts provided guidelines and recommendations for the optimal strategies to implement follow-up of colon cancer $[16,21,22]$. One of the potential limitations is the lack of stratification of recurrent risk among different cancer stages, since the above recommendations are generically stated for all cancer stages. It is well recognized that early stages of colon cancer have a lower risk of relapse, and therefore, more accurate strategies for optimizing and tailoring surveillance protocols might be proposed. A risk-adapted follow-up in which the intensity varies according to the risk of recurrence might increase the cost-effectiveness by concentrating resources on patients at high risk. Selective use of intensive followup regimens, excluding patients at low risk for recurrence and patients who cannot tolerate further curative resection while concentrating on subpopulations of patients at high risk, may increase the utility of such regimens and thus improve efficacy. Continued improvements in risk stratification, disease detection, and treatment might increase the benefits of postoperative surveillance.

In this line of thought, we analyzed the overall and disease-free survival rates of patients with stage I, IIA, and IIB to evaluate if among these subjects we might find specific variables useful to identify cohorts with low or high risk of recurrence in order to split subgroups in which follow-up may be more of less intensive in term of time intervals of visits and diagnostic workup.

Our 5-year follow-up data are in accordance with recent large series [23] reporting overall and disease-free survival rates. Recurrent time and site were also quite consistent with other reports [21, 24]. In our series, $82 \%$ of the patients were diagnosed with recurrence within 2 years and in all but one case, relapse was detected by US or CT scan.

By substage analyses, we found that overall and diseasefree survival curves of stage I and IIA were almost 
Table $\mathbf{2}$ Characteristics of the overall population and of patients with or without recurrence

\begin{tabular}{|c|c|c|c|c|}
\hline Characteristic & Total & Recurrence & Non recurrence & $p$ value \\
\hline Overall patients & 196 & $11(5.6)$ & $185(94.4)$ & \\
\hline \multicolumn{5}{|l|}{ Gender } \\
\hline Male & $117(59.7)$ & $5(45.5)$ & $112(60.5)$ & \multirow[t]{2}{*}{0.356} \\
\hline Female & $79(40.3)$ & $6(54.5)$ & $73(39.5)$ & \\
\hline Median age (range), years & $70(40-89)$ & $71(63-81)$ & $70(40-89)$ & 0.262 \\
\hline \multicolumn{5}{|l|}{ ASA score } \\
\hline 1 & 7 (3.6) & 0 & $7(3.8)$ & \multirow[t]{4}{*}{0.661} \\
\hline 2 & $116(59.2)$ & $7(63.6)$ & $109(58.9)$ & \\
\hline 3 & $66(33.7)$ & $3(27.3)$ & $63(34.1)$ & \\
\hline 4 & 7 (3.6) & $1(9.1)$ & $6(3.2)$ & \\
\hline \multicolumn{5}{|l|}{ Tumor site } \\
\hline Right colon & $83(42.3)$ & $2(18.2)$ & $81(43.8)$ & \multirow[t]{4}{*}{0.009} \\
\hline Trasversum colon & $17(8.7)$ & 0 & $17(9.2)$ & \\
\hline Left colon & $94(48.0)$ & $8(72.7)$ & $86(46.5)$ & \\
\hline$>1$ location & $2(1.0)$ & $1(9.1)$ & $1(0.5)$ & \\
\hline \multicolumn{5}{|l|}{ T } \\
\hline 1 & $10(5.1)$ & 0 & $10(5.4)$ & \multirow[t]{4}{*}{0.772} \\
\hline 2 & $56(28.6)$ & $3(27.3)$ & $53(28.6)$ & \\
\hline 3 & $121(61.7)$ & $7(63.6)$ & $114(61.6)$ & \\
\hline $4 a$ & $9(4.6)$ & $1(9.1)$ & $8(4.3)$ & \\
\hline \multicolumn{5}{|l|}{ Stage } \\
\hline 1 & $65(33.2)$ & $3(27.3)$ & $62(33.5)$ & \multirow[t]{3}{*}{0.726} \\
\hline $2 \mathrm{~A}$ & $122(62.2)$ & $7(63.6)$ & $115(62.2)$ & \\
\hline $2 \mathrm{~B}$ & $9(4.6)$ & $1(9.1)$ & $8(4.3)$ & \\
\hline \multicolumn{5}{|l|}{ Grading } \\
\hline 1 & $15(7.7)$ & 0 & $15(8.1)$ & \multirow[t]{3}{*}{0.349} \\
\hline 2 & $166(84.7)$ & $11(100)$ & $155(83.8)$ & \\
\hline 3 & $15(7.7)$ & 0 & $15(8.1)$ & \\
\hline \multicolumn{5}{|l|}{ Lymph nodes retrieved } \\
\hline$>=12$ & $153(78.1)$ & $6(54.5)$ & $147(79.5)$ & \multirow[t]{2}{*}{0.066} \\
\hline$<12$ & $43(21.9)$ & $5(45.5)$ & $38(20.5)$ & \\
\hline \multicolumn{5}{|l|}{ Vascular invasion } \\
\hline yes & $9(4.6)$ & $2(18.2)$ & $7(3.8)$ & \multirow[t]{2}{*}{0.083} \\
\hline no & $187(95.4)$ & $9(81.8)$ & $178(96.2)$ & \\
\hline \multicolumn{5}{|l|}{ Lymphatic invasion } \\
\hline yes & $32(16.3)$ & $4(36.4)$ & $28(15.1)$ & \multirow[t]{2}{*}{0.084} \\
\hline no & $164(83.7)$ & $7(63.6)$ & $157(84.9)$ & \\
\hline \multicolumn{5}{|l|}{ Growth } \\
\hline Infiltrative & $108(55.1)$ & $7(63.6)$ & $101(54.6)$ & \multirow[t]{2}{*}{0.784} \\
\hline Expansive & $88(44.9)$ & $4(36.4)$ & $84(45.4)$ & \\
\hline \multicolumn{5}{|l|}{ Lymphocyte infiltration } \\
\hline no & $60(30.6)$ & $6(54.5)$ & $54(29.2)$ & \multirow[t]{3}{*}{0.301} \\
\hline small & $19(9.7)$ & $1(9.1)$ & $18(9.7)$ & \\
\hline small-moderate & $71(36.2)$ & $2(18.2)$ & $69(37.3)$ & \\
\hline
\end{tabular}


Table 2 Characteristics of the overall population and of patients with or without recurrence (Continued)

\begin{tabular}{|c|c|c|c|c|}
\hline moderate & $22(11.2)$ & 0 & $22(11.9)$ & \\
\hline severe & $24(12.2)$ & $2(18.2)$ & $22(11.9)$ & \\
\hline \multicolumn{5}{|l|}{ Setting } \\
\hline elective surgery & 180 (91.8) & $11(100)$ & $169(91.4)$ & \multirow[t]{2}{*}{0.605} \\
\hline emergency & $16(8.2)$ & 0 & $16(8.6)$ & \\
\hline \multicolumn{5}{|l|}{ Blood transfusions } \\
\hline no & $164(83.7)$ & $10(90.9)$ & $151(81.6)$ & \multirow[t]{2}{*}{0.707} \\
\hline yes & 35 (16.3) & $1(9.1)$ & $34(18.4)$ & \\
\hline \multicolumn{5}{|l|}{ Fibrosis } \\
\hline 10 & $100(51.0)$ & $3(27.3)$ & $97(52.4)$ & \multirow[t]{10}{*}{0.054} \\
\hline 20 & $28(14.3)$ & $2(18.2)$ & $26(14.1)$ & \\
\hline 30 & $22(11.2)$ & $2(18.2)$ & $20(10.8)$ & \\
\hline 40 & $12(6.1)$ & $1(9.1)$ & $11(5.9)$ & \\
\hline 50 & $12(6.1)$ & 0 & $12(6.5)$ & \\
\hline 60 & $8(4.1)$ & 0 & $8(4.3)$ & \\
\hline 70 & $11(5.6)$ & $2(18.2)$ & $9(4.9)$ & \\
\hline 80 & $3(1.5)$ & $1(9.1)$ & $2(1.1)$ & \\
\hline 90 & 0 & 0 & 0 & \\
\hline 100 & 0 & 0 & 0 & \\
\hline \multicolumn{5}{|l|}{ Fibrosis grade } \\
\hline High (> = $50 \%)$ & $34(17.3)$ & $3(27.3)$ & $31(16.8)$ & \multirow[t]{2}{*}{0.408} \\
\hline Low (<50 \%) & $162(82.7)$ & $8(72.7)$ & $154(83.2)$ & \\
\hline \multicolumn{5}{|l|}{ Budding } \\
\hline High ( $>=10$ foci) & 38 (19.4) & $4(36.4)$ & 34 (18.4) & \multirow[t]{2}{*}{0.229} \\
\hline Low (<10 foci) & 158 (80.6) & $7(63.6)$ & $151(81.6)$ & \\
\hline
\end{tabular}

Data are number of patients (\%) or median (range) when specified

Table 3 Characteristics of the eleven patients with recurrent disease

\begin{tabular}{|c|c|c|c|c|c|c|}
\hline Patient & Initial stage & $\begin{array}{l}\text { Adjuvant chemotherapy } \\
\text { after surgery }\end{array}$ & Site of recurrence & $\begin{array}{l}\text { Presence of } \\
\text { symptoms }\end{array}$ & $\begin{array}{l}\text { Timing of recurrence } \\
\text { (months) }\end{array}$ & $\begin{array}{l}\text { Diagnostic } \\
\text { tool }\end{array}$ \\
\hline 1 & I & No & Liver & No & 6 & CEUS and $\mathrm{CT}$ \\
\hline 2 & I & No & Local and lung & No & 24 & CEUS and $\mathrm{CT}$ \\
\hline 3 & $\| \mathrm{A}$ & No & Lung & No & 48 & $C T$ \\
\hline 4 & $\| \mathrm{A}$ & No & Liver & No & 18 & CEUS and $\mathrm{CT}$ \\
\hline 5 & $\| \mathrm{A}$ & Yes & Lung & No & 18 & $C T$ \\
\hline 6 & $\| A+I$ & No & Liver & No & 18 & $C T$ \\
\hline 7 & $\| \mathrm{A}$ & No & Liver & Abdominal pain & 42 & CEUS and $\mathrm{CT}$ \\
\hline 8 & $\| \mathrm{A}$ & Yes & Lung & No & 24 & $C T$ \\
\hline 9 & $\| \mathrm{A}$ & No & Local & No & 12 & $C T$ \\
\hline 10 & I & No & Local & No & 12 & Colonoscopy \\
\hline 11 & $\| \mathrm{B}$ & No & Liver & No & 12 & $C T$ \\
\hline
\end{tabular}



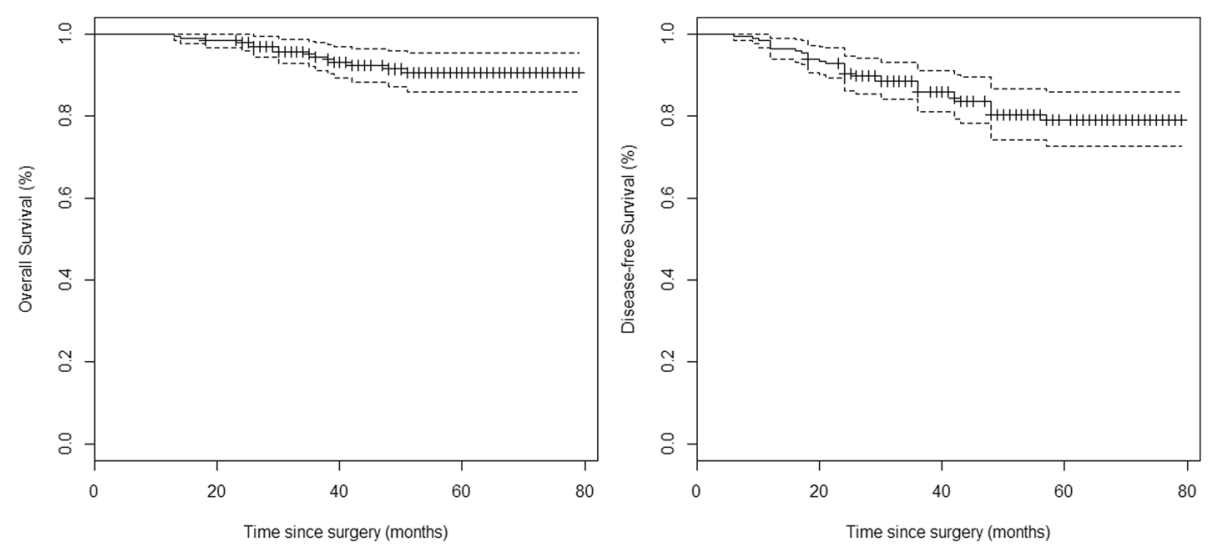

Fig. 1 Kaplan-Meier curves for overall survival and disease-free survival. Marks at censoring times. Bands are $95 \%$ confidential intervals

overlapping while stage IIB had a negative impact on cancer-related mortality. With the intrinsic limitation of the small number of patients in our series, the present results confirm that stage IIB should be considered as a subgroup with poorer prognosis [25].

By analyzing the impact of single risk factors on recurrence, we observed that left or double site cancer were negative prognostic variables. This relationship between relapse and tumor location is not clear, but it may be related to tumor biology. One specific aspect of tumor biology is microsatellite instability (MSI). Multiple studies $[5,26]$ found that patients with MSI-positive tumors have a better overall prognosis and that MSI status is an independent positive predictor of survival. MSI is predominantly seen in right-sided colon cancers, and less than $5 \%$ of left-sided cancers show MSI. Probably, in the next future, it will be necessary to include routinely MSI description in pathologic specimens to obtain a higher prognostic performance.

Several investigators aimed to identify a specific "ideal minimum" number of nodes to be reported. There has been great variation between studies in terms of identifying an "ideal minimum" number of nodes to be examined in stage II cancers, with figures ranging from 6 to 17 nodes [27-29]. An accurate description of node involvement may be particularly important in stage II tumors for a number of reasons. Firstly, the identification of a specific figure provides an indicator as to where it can be stated with defined certainty that the risk of long-term mortality is reduced $[28,29]$. Secondly, it provides an important means of institutional quality control. Interestingly, the American National Quality Forum has endorsed a number of 12 nodes as a standard for assessing hospital performance in the surgical management of colonic tumors $[27,30]$. Finally, an ideal minimum number of nodes may also be used as a "cut-off" value, below which stage II patients may be offered adjuvant chemotherapy [27].
In the present reports, the rate of patients with less than 12 nodes retrieved was $22 \%$. This figure is in line with other large series [31, 32], advocating that this is a common and worldwide problem, since this represents a negative prognostic factor $[3,33]$ as also suggested by our data.

Recently, tumor budding has been reported as one of the major malignant characteristics of colorectal carcinomas. It is defined as the presence of isolated single cells or small cell clusters (up to four cells) scattered in the stroma at invasive fronts; this represents feature loss of both glandular differentiation and cell cohesion that is crucial for the development of high invasive properties $[6,34]$. Ueno classification divided it into high grade budding ( $\geq 10$ foci) or low grade ( $<10$ foci).

Lai et al. [35] reported that, in his experience, tumor budding is an important prognostic parameter for cancer-specific outcomes in patients with stage II colorectal cancer. They concluded that tumor budding could help to identify high-risk patients who might benefit from adjuvant chemotherapy. Othsuki et al. [36] demonstrated a significant difference in disease-free survival using our definition (high grade $\geq 10$ foci, low grade $<10$ foci). Likely, our negative results were related to the relative low number of patients or for the inclusion of patient in stage I, and the exclusion of rectal cancer.

The presence and the degree of fibrosis in the cancer seems to be another important prognostic negative factor [37]. Mesker et al. [10] proposed a differentiation into high percentage ( $\geq 50 \%$ of fibrosis) and low percentage $(<50 \%)$. Huijbers et al. [9] in a series of 710 patients observed a significant decrease in the overall survival and disease-free survival for the patients with high percentage of fibrosis versus patients with a low percentage of fibrosis (69 vs. $83 \%$ and 58 vs. $77 \%$, respectively) but without differentiating the prognostic ability by stage. Our results suggest that, at least, in early colon cancer stages, fibrosis is not a key prognostic element. 

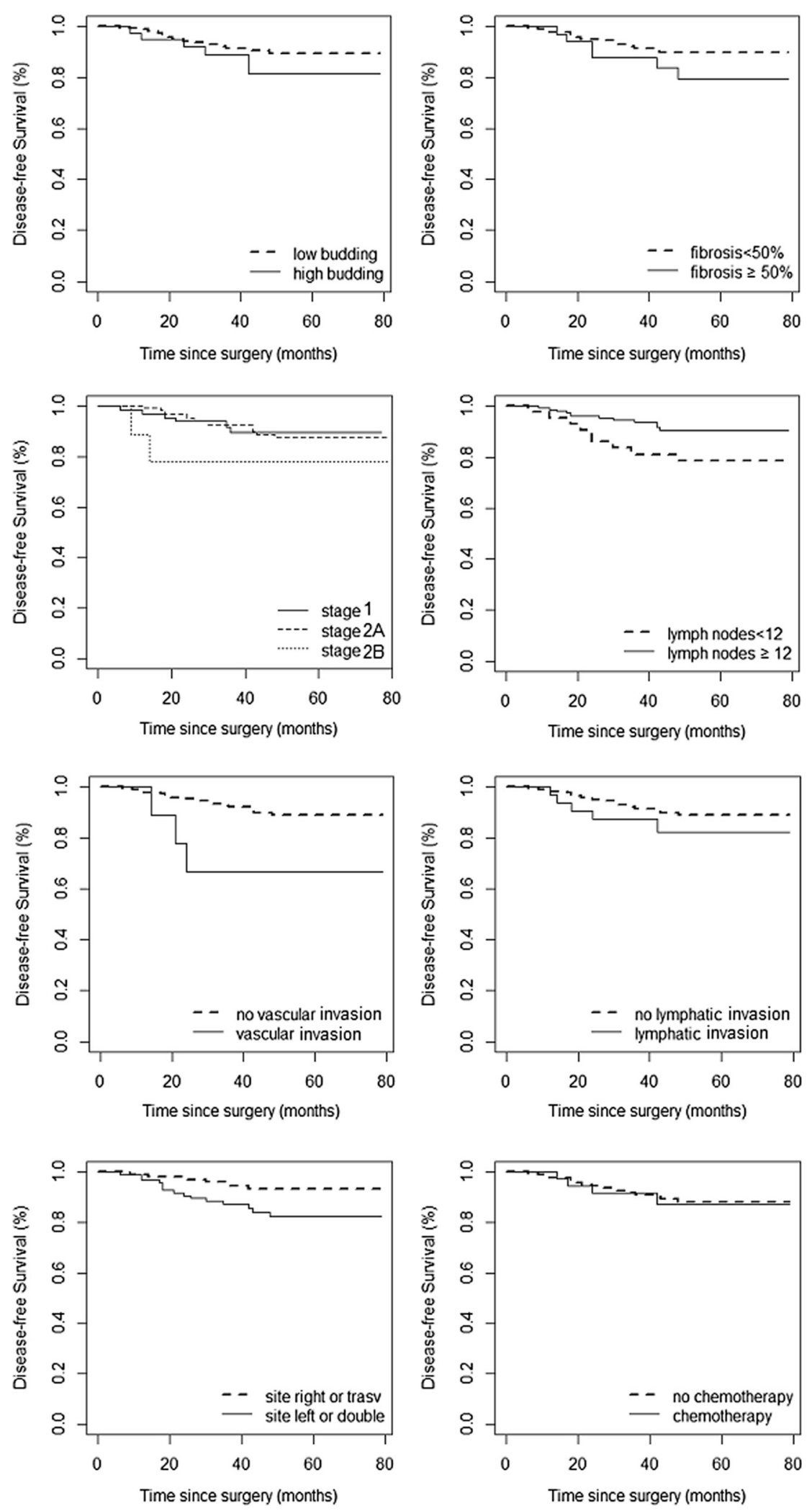

Fig. 2 Kaplan-Meier curves for disease-free survival stratified for specific risk factors such as budding, fibrosis, staging, number of nodes, vascular and lymphatic invasion, tumor site, and adjuvant chemotherapy 

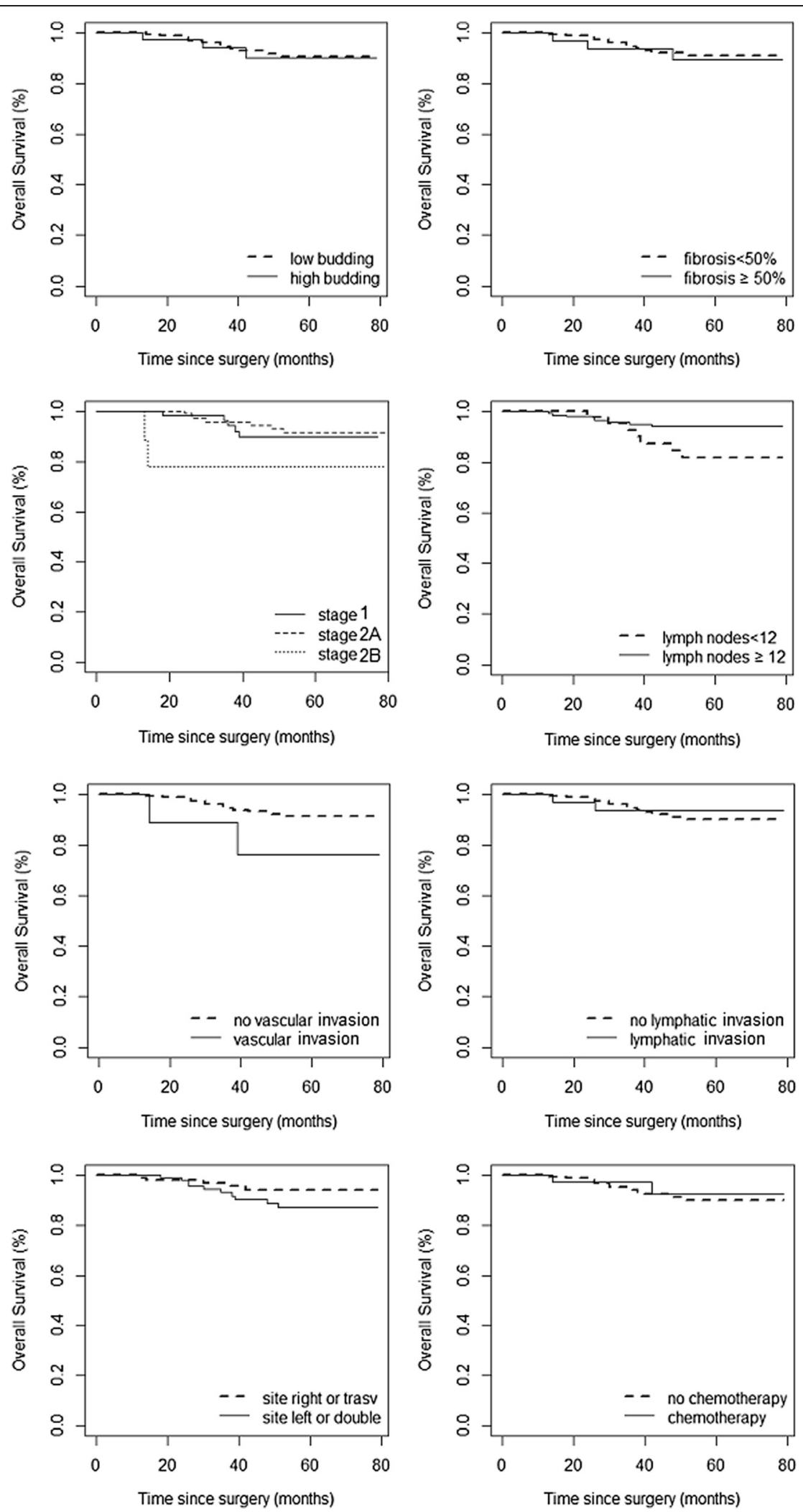

Fig. 3 Kaplan-Meier curves for overall survival stratified for specific risk factors such as budding, fibrosis, staging, number of nodes, vascular and lymphatic invasion, tumor site and adjuvant chemotherapy 
Table 4 Risk factors analyzed by univariate and multivariate (Cox regression models) for disease-free survival (DFS) and overall survival (OS)

\begin{tabular}{|c|c|c|c|c|}
\hline & \multicolumn{2}{|l|}{ Univariate analysis } & \multicolumn{2}{|c|}{ Multivariate analysis } \\
\hline & DFS HR $(95 \% \mathrm{Cl})$ & OS HR $(95 \% \mathrm{Cl})$ & DFS HR $(95 \% \mathrm{Cl})$ & OS HR $(95 \% \mathrm{Cl})$ \\
\hline \multicolumn{5}{|l|}{ Gender } \\
\hline Female & 1 & 1 & 1 & 1 \\
\hline Male & $0.59(0.25-1.40)$ & $0.57(0.21-1.57)$ & $0.41(0.16-1.05)$ & $0.41(0.14-1.25)$ \\
\hline Age, years & $1.06(1.01-1.12)$ & $1.09(1.02-1.16)$ & $1.07(1.01-1.12)$ & $1.09(1.02-1.16)$ \\
\hline \multicolumn{5}{|l|}{ Budding } \\
\hline No & 1 & 1 & 1 & 1 \\
\hline Yes & $1.72(0.67-4.44)$ & $1.09(0.31-3.85)$ & $1.22(0.35-4.16)$ & $1.06(0.23-4.87)$ \\
\hline \multicolumn{5}{|l|}{ Fibrosis } \\
\hline$<50 \%$ & 1 & 1 & 1 & 1 \\
\hline$>=50 \%$ & $1.98(0.77-5.10)$ & $1.23(0.35-4.35)$ & $1.21(0.37-3.94)$ & $1.01(0.22-4.61)$ \\
\hline \multicolumn{5}{|l|}{ Stage } \\
\hline 1 & 1 & 1 & 1 & 1 \\
\hline $2 \mathrm{~A}$ & $1.11(0.42-2.93)$ & $0.80(0.26-2.46)$ & $1.08(0.35-3.30)$ & $1.13(0.31-4.13)$ \\
\hline $2 B$ & $2.89(0.58-14.35)$ & $3.68(0.71-19.00)$ & $4.07(0.63-26.08)$ & $5.81(0.77-43.92)$ \\
\hline \multicolumn{5}{|l|}{ Lymph nodes retrieved } \\
\hline$>=12$ & 1 & 1 & 1 & 1 \\
\hline$<12$ & $2.56(1.09-6.25)$ & $2.70(1.03-7.69)$ & $2.13(0.76-5.88)$ & $2.38(0.71-8.33)$ \\
\hline \multicolumn{5}{|l|}{ Vascular invasion } \\
\hline No & 1 & 1 & 1 & 1 \\
\hline Yes & $3.78(1.12-12.91)$ & $3.19(0.72-14.15)$ & $3.43(0.87-13.58)$ & $2.91(0.59-14.31)$ \\
\hline \multicolumn{5}{|l|}{ Lymphatic invasion } \\
\hline No & 1 & 1 & 1 & 1 \\
\hline Yes & $1.71(0.63-4.67)$ & $0.83(0.19-3.69)$ & $0.88(0.26-2.94)$ & $0.85(0.09-2.89)$ \\
\hline \multicolumn{5}{|l|}{ Site } \\
\hline Right or trasversum & 1 & 1 & 1 & 1 \\
\hline Left or double & $2.69(1.04-6.93)$ & $2.06(0.70-6.04)$ & $3.56(1.24-10.21)$ & $3.34(0.98-11.84)$ \\
\hline \multicolumn{5}{|l|}{ Chemotherapy } \\
\hline No & 1 & 1 & 1 & 1 \\
\hline Yes & $1.12(0.38-3.34)$ & $0.76(0.17-3.37)$ & $1.52(0.39-5.97)$ & 1.37 0.24-7.99) \\
\hline
\end{tabular}

In 2010, the European Society of Medical Oncology stated that the use of adjuvant chemotherapy in stage II $\mathrm{CC}$ remains controversial. In general, stage IIA can be considered low risk while stage IIB deserves adjuvant treatment. In stage IIA adjuvant treatment may be considered in the presence of unfavorable prognostic factors: obstruction or perforation debut, contiguity infiltration of neighboring organs, high grading, number of lymph nodes examined $<12$ and vascular, perineural or lymphatic infiltration [25]. Our policy was to candidate patients to adjuvant chemotherapy in stage IIB and in stage IIA only when at least two of the above risk factors were present. This conservative policy was based on the recommendations available at the time the study initiated. In fact, evidence from randomized controlled trials did not support the use of adjuvant chemotherapy, even for patients with high-risk stage II colon cancer [38] or at most when at least two risk factors were present [39].

\section{Conclusions}

In conclusion, the present results suggest that staging remains of paramount importance in detecting patients at high risk of recurrence and in assigning a correct prognosis of long-term survival. The number of lymph nodes retrieved, the presence of vascular invasion, and the left 
or multiple cancer location are negative prognostic factors and should be take into account for the possibility of additional therapies. The detection of fibrosis and budding do not seem to add valuable information for prognosis. In early colon cancer stages, the surveillance program should be maximized within the first 2 years.

\section{Competing interests}

The authors declare that they have no competing interests.

\section{Authors' contribution}

EG was responsible for the follow-up program, conceived the study, and drafted the manuscript. DPB was responsible for database quality and performed the statistical analysis. SP, ML, MG coordinated the follow-up strategies, helped to draft the manuscript, and participated to the study design. NZ and GB performed histopathology and drafted the manuscript. $M T$ and $A B$ were the coordinators of the colorectal cancer program and participated in the study design. LG was the study design coordinator, the principal investigator, and also drafted the manuscript. All authors read and approved the final manuscript.

\section{Author details}

Department of Surgery and Translational Medicine, Milano-Bicocca University, San Gerardo Hospital, Monza, Italy. ²Department of Health Science, Centre of Biostatistics for Clinical Epidemiology, Milano-Bicocca University, Monza, Italy. ${ }^{3}$ Unit of Pathology, San Gerardo Hospital, Monza, Italy. ${ }^{4}$ Department of Surgery, San Gerardo Hospital (4ªno A), Via Pergolesi 33, 20052 Monza, Italy.

\section{Received: 25 March 2015 Accepted: 5 August 2015}

Published online: 28 August 2015

\section{References}

1. Gianotti L, Tamini N, Nespoli L, Rota M, Bolzonaro E, Frego R, et al. A prospective evaluation of short-term and long-term results from colonic stenting for palliation or as a bridge to elective operation versus immediate surgery for large-bowel obstruction. Surg Endosc. 2013;27:832-42.

2. Gunderson LL, Jessup JM, Sargent DJ, Greene FL, Stewart AK. Revised TN. Categorization for colon cancer based on national survival outcomes data. J Clin Oncol. 2010;28:264-71.

3. Vather R, Sammour T, Kahokehr A, Connolly AB, Hill AG. Lymph node evaluation and long-term survival in Stage II and Stage III colon cancer: a national study. Ann Surg Oncol. 2009;16(3):585-93.

4. Compton CC, Fielding LP, Burgart LJ, Conley B, Cooper HS, Hamilton SR, et al. Prognostic factors in colorectal cancer. College of American Pathologists Consensus Statement 1999. Arch Pathol Lab Med. 2000;124:979-94

5. Merok MA, Ahlquist T, Røyrvik EC, Tufteland KF, Hektoen M, Sjo OH, et al. Microsatellite instability has a positive prognostic impact on stage II colorectal cancer after complete resection: results from a large, consecutive Norwegian series. Ann Oncol. 2013;24:1274-82.

6. Ueno H, Murphy J, Jass JR, Mochizuki H, Talbot IC. Tumour 'budding' as an index to estimate the potential of aggressiveness in rectal cancer. Histopathology. 2002;40:127-32.

7. Ueno H, Mochizuki H, Hashiguchi Y, Shimazaki H, Aida S, Hase K, et al. Risk factors for an adverse outcome in early invasive colorectal carcinoma. Gastroenterology. 2004;127:385-94.

8. Prall F, Nizze $H$, Barten M. Tumor budding as prognostic factor in stage $\mathrm{I} / \mathrm{II}$ colorectal carcinoma. Histopathology. 2005:47:17-24

9. Huijbers A, Tollenaar RA, vPelt GW, Zeestraten EC, Dutton S, McConkey CC, et al. The proportion of tumor stroma as a strong prognosticator for stage ॥ and III colon cancer patients: validation in the VICTOR trial. Ann Oncol. 2013:24:179-85.

10. Mesker WE, Junggeburt JM, Szuhai $K$, de Heer $P$, Morreau $H$, Tanke HJ, et al. The carcinoma-stroma ratio of colon carcinoma is an independent fact of survival compared to lymph node status and tumor stage. Cell Oncol. 2007;29:387-98.

11. Törnqvist A, Ekelund G, Leandoer L. Early diagnosis of metachronous colorectal carcinoma. Aust NZJ Surg. 1981;51:442-5.
12. Heald RJ, Lockhart-Mummery HE. The lesion of the second cancer of the large bowel. Br J Surg. 1972;59:16-9.

13. Castells A, Bessa X, Daniels M, Ascaso C, Lacy AM, García-Valdecasas JC, et al. Value of postoperativen surveillance after radical surgery for colorectal cancer. Results of a cohort study. Dis Colon Rectum. 1998;41:714-24.

14. Renehan AG, Egger M, Saunders MP, O'Dwyer ST. Impact on survival of intensive follow-up after curative resection for colorectal cancer: systematic review and meta-analysis of randomized trials. BMJ. 2002;324(7341):813.

15. Bruinvels D, Stiggelbout A, Kievit J, Van Houwelingen H, Habbema J, Van de Velde C. Follow-up of patients with colorectal cancer. A meta-analysis. Ann Surg. 1994;219:174-82.

16. Jefferey M, Hickey $B$, Hider P. Follow-up strategies for patients treated for non metastatic colorectal cancer. Cochrane Database Syst Rev. 2007;1, CD002200.

17. Tjandra J, Chan M. Follow-up after curative resection of colorectal cancer: a meta-analysis. Dis Colon Rectum. 2007;50:1783-99.

18. Scholefield JH, Steele RJ. Guidelines for follow up after resection of colorectal cancer. Gut. 2002;51 Suppl 5:V3-5

19. Edge S, Byrd DR, Compton CC, Fritz AG, Greene FL, Trotti A. AJCC cancer staging manual. 7th ed. 2010. revised 2013.

20. Figueredo A, Rumble RB, Maroun J, Earle CC, Cummings B, McLeod R, et al. Follow-up of patients with curatively resected colorectal cancer: a practice guideline. BMC Cancer. 2003;3:26-32.

21. Buie WD, Attard JA. Follow up recommendations for colon cancer. Clin Colon Rectal Surg. 2005;18:232-43.

22. Hammod K, Margolin DA. The role of postoperative surveillance in colorectal cancer. Clin Colon Rectal Surg. 2007:20:249-54.

23. Hari DM, Leung AM, Lee JH, Sim MS, Vuong B, Chiu CG, et al. AJCC Cancer Staging Manual 7th edition criteria for colon cancer: do the complex modifications improve prognostic assessment? J Am Coll Surg. 2013:217:181-90.

24. Tsikitis VL, Malireddy K, Green EA, Christensen B, Whelan R, Hyder J, et al. Postoperative surveillance recommendations for early stage colon cancer based on results from the clinical outcomes of surgical therapy trial. J Clin Oncol. 2009;27:3671-6.

25. Labianca R, Nordlinger B, Beretta GD, Brouquet A, Cervantes A. ESMO Guidelines Working Group. Primary colon cancer: ESMO Clinical Practice Guidelines for diagnosis, adjuvant treatment and follow-up. Ann Oncol. 2010;21 Suppl 5:v70-7.

26. Arnold CN, Goel A, Blum HE, Boland CR. Molecular pathogenesis of colorectal cancer. Cancer. 2005;104:2035-47.

27. Chang GJ, Rodriguez-Bigas MA, Skibber JM, Moyer VA. Lymph node evaluation and survival after curative resection of colon cancer: systematic review. J Natl Cancer Inst. 2007;99:433-41.

28. Swanson RS, Compton CC, Stewart AK, Bland KI. The prognosis of T3N0 colon cancer is dependent on the number of lymph nodes examined. Ann Surg Oncol. 2003;10:65-71.

29. Wong $\mathrm{JH}$, Severino R, Honnebier MB, Tom P, Namiki TS. Number of nodes examined and staging accuracy in colorectal carcinoma. J Clin Oncol. 1999;17:2896-900.

30. National Quality Forum. Specifications of the national voluntary consensus standards for breast and colon cancer. http://www.qualityforum.org/Publications/ 2009/05/National_Voluntary_Consensus_Standards_for_Quality_of_Cancer Care.aspx. Accessed 18 Jan 2007.

31. Weiss JM, Pfau PR, O'Connor ES, King J, LoConte N, Kennedy G, et al. Mortality by stage for right- versus left-sided colon cancer: analysis of surveillance, epidemiology, and end results—-medicare data. J Clin Oncol. 2011;29:4401-9.

32. Dillman RO, Aaron K, Heinemann FS. McClure SEldentification of 12 or more lymph nodes in resected colon cancer specimens as an indicator of quality performance. Cancer. 2009;115:1840-8.

33. Law CH, Wright FC, Rapanos T, Alzahrani M, Hanna SS, Khalifa M, et al. Impact of lymph node retrieval and pathological ultra-staging on the prognosis of stage II colon cancer. J Surg Oncol. 2003;84:120-6.

34. Xu CJ, Mikami T, Nakamura T, Tsuruta T, Nakada N, Yanagisawa N, et al. Tumor budding, myofibroblast proliferation, and fibrosis in obstructing colon carcinoma: the roles of Hsp47 and basic fibroblast growth factor. Pathol Res Pract. 2013;209:69-74.

35. Lai YH, Wu LC, Li PS, Wu WH, Yang SB, Xia P, et al. Tumour budding is a reproducible index for risk stratification of patients with stage II colon cancer. Colorectal Dis. 2014;16:259-64. 
36. Ohtsuki K, Koyama F, Tamura T, Enomoto Y, Fujii H, Mukogawa T, et al. Prognostic value of immunohistochemical analysis of tumor budding in colorectal carcinoma. Anticancer Res. 2008;28:1831-6.

37. Kanazawa H, Mitomi H, Nishiyama Y, Kishimoto I, Fukui N, Nakamura T, et al. Tumor budding at invasive margins and outcome in colorectal cancer. Colorectal Dis. 2008;10:41-7.

38. Benson 3rd AB, Schrag D, Somerfield MR, Cohen AM, Figueredo AT, Flynn PJ, et al. American Society of Clinical Oncology recommendations on adjuvant chemotherapy for stage II colon cancer. J Clin Oncol. 2004;22:3408-19.

39. Gertler R, Rosenberg R, Schuster T, Friess H. Defining a high-risk subgroup with colon cancer stages I and II for possible adjuvant therapy. Eur J Cancer. 2009;45:2992-9.

\section{Submit your next manuscript to BioMed Central and take full advantage of:}

- Convenient online submission

- Thorough peer review

- No space constraints or color figure charges

- Immediate publication on acceptance

- Inclusion in PubMed, CAS, Scopus and Google Scholar

- Research which is freely available for redistribution 